\title{
Evaluation of the undersea habitats - Tektite II, Hydro-Lab, and Edalhab - for scientific saturation diving programs
}

\author{
W. L. High, I. E. Ellis, W. W. Schroeder \& G. Loverich \\ U. S. Department of Commerce, NOAA Nortbwest Fisheries Center; \\ Seattle, Washington, USA
}

\begin{abstract}
KURZFASSUNG: Bewertung der Unterwasser-Habitate Tektite II, Hydro-Lab und Edalhab für Programme des wissenschaftlichen Sättigungstauchens. Eine kritische Bewertung der 3 Unterwasserlaboratorien Tektite II, Hydro-Lab und Edalhab wird auf Grund der praktischen Erfahrungen vorgenommen, die während eines längeren bemannten Einsatzes unter Sätrigungsbedingungen im Rahmen eines biologischen Forschungsprogrammes in den USA gewonnen wurden. Keines der erprobten Unterwasser-Systeme erfüllte alle Erwartungen. Alle Habitate wiesen sowohl zufriedenstellende als auch mangelhafte Eigenschaften auf, die ausführlich diskutiert werden. Unter Berüdksichtigung der bisher gemachten Erfahrungen werden zahlreiche Anregungen zur Verbesserung von Unterwasserlaboratorien und Empfehlungen für Taucheinsätze mitgeteilt.
\end{abstract}

\section{INTRODUCTION}

Undersea habitats are designed, constructed, and operated to serve as shelters and laboratories for scientists, engineers, and technicians conducting extended experiments on or near the ocean floor.

The undersea habitats and support systems have evolved beyond a scientific and engineering novelty to a useful tool for Man-in-the-Sea programs. The original systems, having successfully proven that human beings can function efficiently and perform meaningful experiments in the underwater environment, have also provided important information and experience that should be incorporated into advanced habitat systems.

Although the design of a habitat program is a compromise between inputs based upon engineering, operations, economics, and utility, the major justification for the habitats is not the habitat itself but the extension of man's knowledge through the use of habitats.

The authors, each having made one or more saturation dives in conjunction with a habitat program, will review some merits and limitations of three different habitat systems functioning as undersea laboratories (Tektite II, sponsored by the U.S. Department of Interior in 1970; Hydro-Lab, sponsored by the U.S. Department of 
Commerce in 1971; and Edalhab, primarily sponsored by the U.S. Department of Commerce in 1972). We will describe systems and components which affect the desirability of habitats, compare merits and limitations of these features, and recommend an undersea system that best meets our present criteria. Our discussion will be of a qualitative nature and directed toward increasing the flexibility, performance, and output of future habitat systems.

These dives were made as segments of extended programs; therefore, conditions or procedures described here may not have continued throughout all missions. Many changes did occur when correctable deficiencies were discovered.

Most information comes from experiences during Tektite II Mission I-50 (HIGH), Mission 4-50 (Schroeder), Hydro-Lab NOAA Mission I (High, Schroeder, Ellis), and Edalhab FLARE (Florida Aquanaut Research Expedition) Mission I (HIgH, ELLIS, LOVERICH) - although valuable contributions were also made by other aquanauts and surface support personnel.

We recognize the difficulty of comparing three different systems, as purposes for the systems were very different (Tektite, a long term facility, Hydro-Lab for short duration dives, and Edalhab primarily a training and teaching aid). They are comparable, however, since they share a common goal - that of providing shelter for scientists working in the sea. For the most part each of the features discussed here differs for the three habitats. Obviously, Tektite because of its great size, cost, and relatively elaborate furnishings provided considerable comfort (NowLis et al. 1971). Hydro-Lab and Edalhab, although spartan, demonstrate the many advantages of small habitats.

One habitat cannot be made to perfectly serve all possible mission goals. For those aquanauts who spent 60 days in Tektite 1 , it was probably just barely large enough. It would be impractical to schedule long-term missions from either small habitat discussed here.

\section{DESCRIPTION OF HABITATS SYSTEMS}

Before discussing in detail the many components of the complete saturationdiving systems, we will provide a general description of each habitat and its support facility.

$$
\text { Hydro-Lab }
$$

Hydro-Lab, although not the smallest facility, was of the simplest design and least expensive to operate, using a self-contained unattended surface life-support buoy. The original cost for the complete system was less than $\$ 60000$. The main structure was an $8-\mathrm{ft}$ diameter by $16 \mathrm{ft}$ long cylinder supported on four short legs 3 feet above the concrete base (Fig. 1). The habitat was submerged by venting ballast tanks in the concrete base and saddle buoyancy tanks located along the habitat cylinder. Pipe fittings which projected from the base permitted the ballast tanks to be filled with air when the habitat was to be raised. 
Entry into the habitat was through a well at one end which also functioned as a lock when the chamber pressure was less than ambient. Although not used during the operations discussed here, personnel could dry transfer from a lockout submersible to the habitat through a tunnel fitted with a mating pedestal. The single room was furnished with two bunks, two folding chairs, a collapsible table, and a small dehumidifier.

A 23-ft long life-support barge floated at the surface above the habitat. Umbilicals carried electrical power and air to Hydro-Lab from a diesel-powered generator and compressor. A 250-gallon water storage tank gravity fed fresh water at ambient temperature to a hand-held shower nozzle next to the entry trunk.

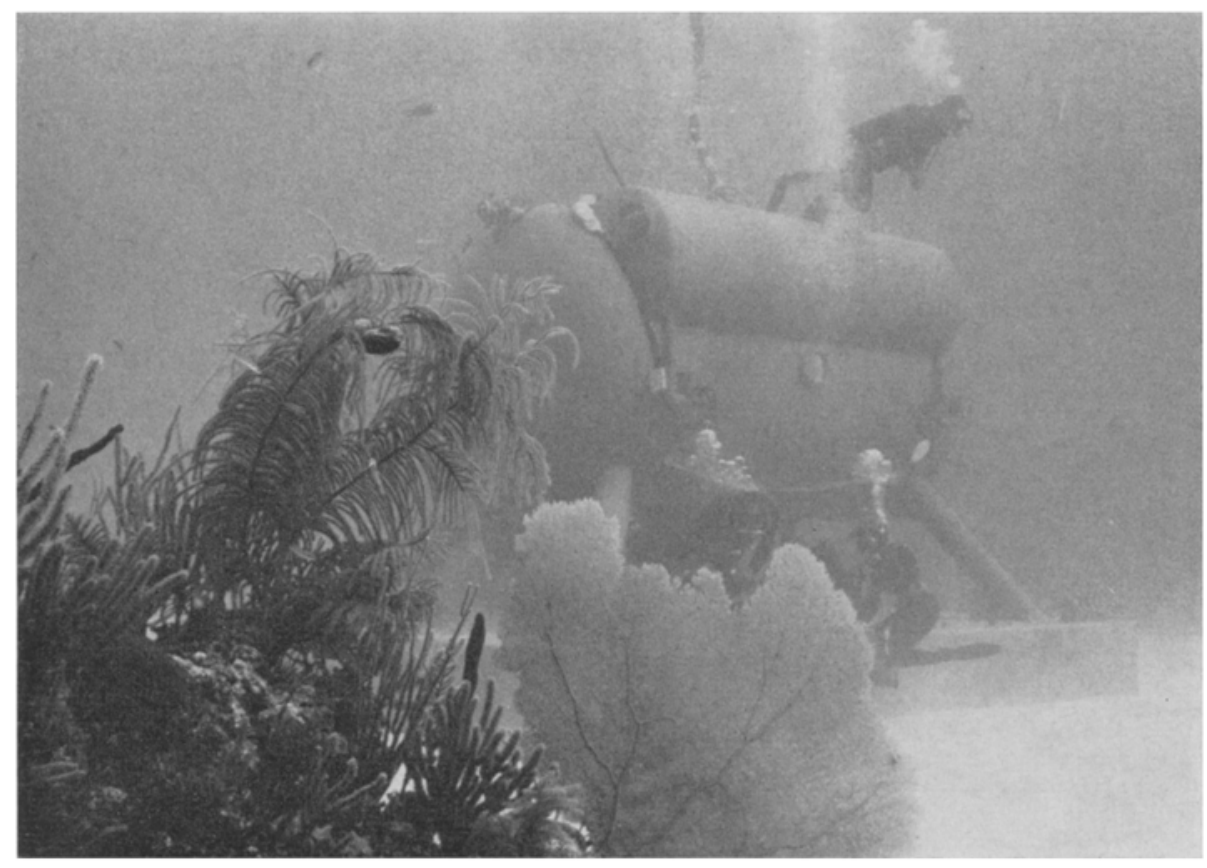

Fig. 1: Hydro-Lab, a small, one-room chamber with spartan living accommodations, rested on the sandy ocean floor adjacent to large coral heads. An unmanned life support barge was connected to the habitat by supply umbilicals

Communications between the aquanauts and surface support personnel about $1^{1 / 4}$ miles away were maintained by a citizens band radio. One diver remained inside the habitat to maintain radio contact. Nearby reefs and some outside diver activity could be viewed through a 3-ft diameter flat glass window at one end of the habitat. Several small ports provided a limited view in other directions. During NOAA Mission I, air cylinders for diver excursions were delivered regularly throughout the day and night by the surface coordinator. Enough units were provided so no delays occurred. 


\section{Edalhab}

Edalhab, the smallest of the three habitats discussed, was designed and built as an engineering design project by students from the University of New Hampshire (Fig. 2). The habitat was constructed mainly of salvaged and donated materials at a cost of about $\$ 20000$. However the support ship R/V LULU used during FLARE cost in excess of $\$ 500000$.

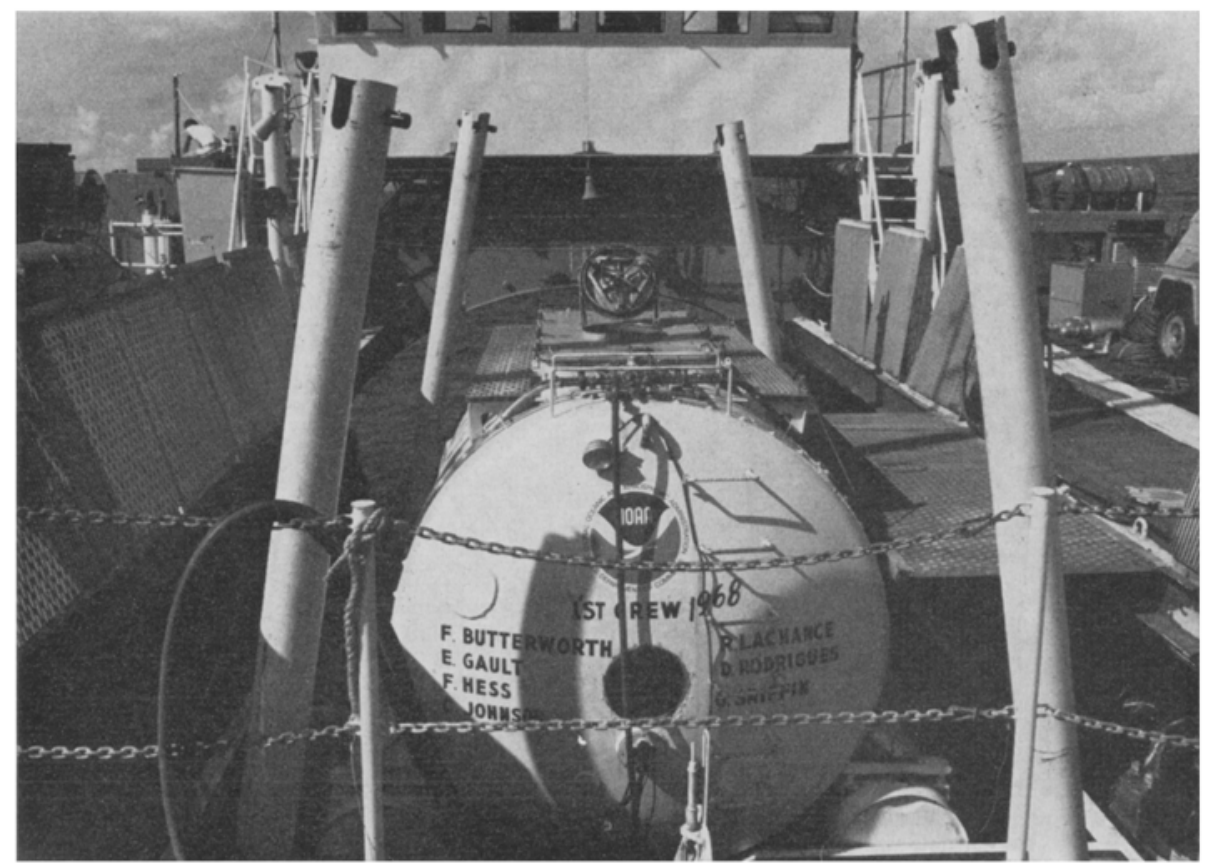

Fig. 2: Edalhab was carried between R/V LULU's catamaran hulls. Four tubular legs were adjusted prior to launch for a selected habitat height above bottom. Note Edalhab's open top hatch which allowed convenient equipment transfer between missions

The living quarters were enclosed in an 8 - $\mathrm{ft}$ diameter by $12-\mathrm{ft}$ long cylinder with a small viewing port at each end. The interior was insulated using $1 / 2$-inch thick unicellular foam. Entry was made through a hatch centrally located in the floor. The interior was well designed, having two permanent bunks (which folded to form a large sear) and a collapsible canvas cot. The interior layout efficiently used the available space and storage areas.

The cylindrical habitat rested on an I-beam frame which, in turn, was supported 8 feet off bottom by four adjustable cylindrical legs. Large (4600 1b) weights suspended from either end of the frame were raised and lowered by diver-operated hand winches. Four large emergency buoyancy tanks were located along the side of the cylinder and could be filled with air through a valve on the habitat exterior. 


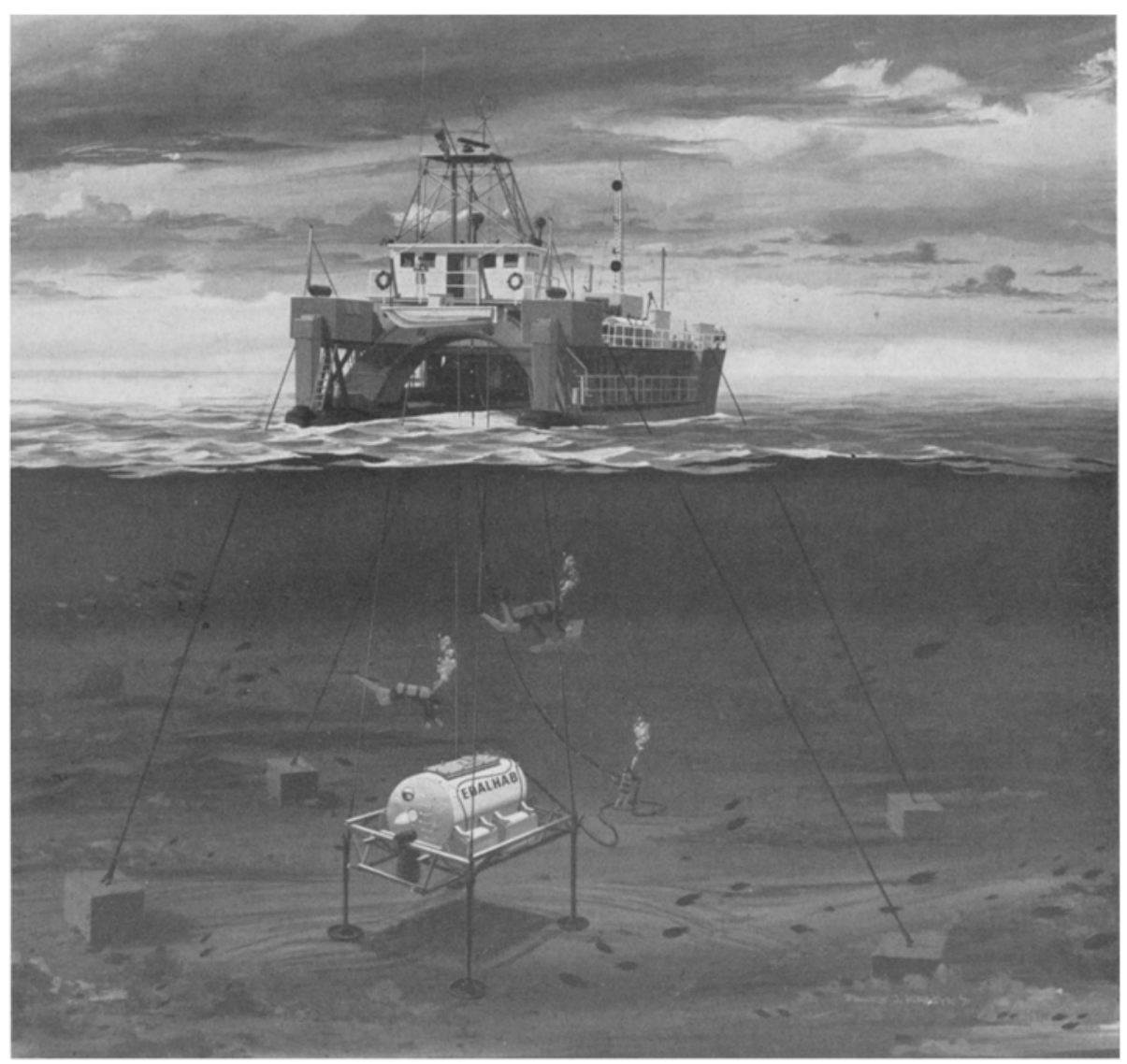

Fig. 3: An artists's drawing of the FLARE habitat system showing Edalhab below the support mothership R/V LULU. The four-point mooring system permitted Edalhab to be lowered to a precise location among coral reefs

R/V LULU, a large catamaran support ship (normally operating with the submersible ALVIN) using a four-point mooring around the habitat site, served as a support platform for the habitat and also as a means of raising, lowering, and transporting Edalhab (Fig. 3). Communications, air, and power were provided from the support ship to the habitat through umbilicals.

\section{Tektite II}

Tektite was constructed as a four-man habitat at a cost of about $\$ 500000$. It was much larger than the other habitats discussed, consisting of two 12-ft by 18-ft connecting cylinders set upon a buoyancy control base (WaLler 1971). The cylinders were divided into four compartments: wet room, engineering, bridge, and crew's 
quarters. Air, water, electrical power, and communications were provided from shore facilities through umbilicals. All systems provided were more sophisticated than for either Hydro-Lab or Edalhab. The environmental control system (ECS) maintained temperature at about $80^{\circ} \mathrm{F}$ with a $65 \%$ relative humidity. Noise levels were low. One or more domed windows in each compartment and a cupola on top of one cylinder permitted the aquanauts excellent viewing in all mid-water and bottom areas adjacent to the habitat.

Tektite II was transported to the diving site on a Navy ISD (landing ship dock) and then floated free. Several days were needed to place the structure on the sea floor. Small iron spheres were shoveled from a barge to ballast compartments in the base of the floating habitat. When about $5000-1 b$ buoyancy remained, hand winches were secured between the habitat base and heavy weights set on the sand below. Then the habitat was pulled down as divers operated the winches. After reaching the bottom, air-filled chambers were vented.

Surface support facilities were several hundred yards from the habitat site. Safety divers operated from a platform at water level, while monitoring personnel and all umbilicaled services were located 100 feet or more above the water on a hill overlooking the bay.

Each room was equipped with a closed circuit television camera and open microphone. The surface watch director, constantly on duty, could monitor each compartment and communicate by voice. Behavioral psychologists continuously monitored activity in the habitat, but they were not permitted to communicate with the divers.

\section{EVALUATION OF HABITAT FEATURES}

\section{Living and working areas}

We have selected for discussion those habitat features that were particularly good or bad. Air quality is not mentioned because it was acceptable. Entry trunk ladders might not have been mentioned had those in the small habitats not been painful to use. They focused attention on the better Tektite ladder design. Because the living and working areas are the most important features of the habitats, they are discussed in detail.

\section{Habitat wet room and entry}

Neither Hydro-Lab nor Edalhab had a wet room space as did Tektite (Fig. 4). Without it, considerable effort was necessarily expended to reduce the amount of wet material brought into the living spaces. The humidity increased to $100 \%$ in both small habitats when the divers entered. This occurred in Hydro-Lab even though returning divers entered the extremely confined trunk one at a time, removed wet suits and accessories which were stored in the trunk or in mesh bags hung outside in the water, and then showered while crouched within the trunk. Hydro-Lab aquanauts either stood waist deep in water or straddled the lower opening, standing on the 
hatch rim. Neither choice was pleasant. During the FLARE program, Edalhab was equipped with a removable grating across the entry trunk. However, when the entry was in use by one diver, none of the other divers out in the water could get up into the hatch. Team members on Mission I constructed a smaller removable platform which

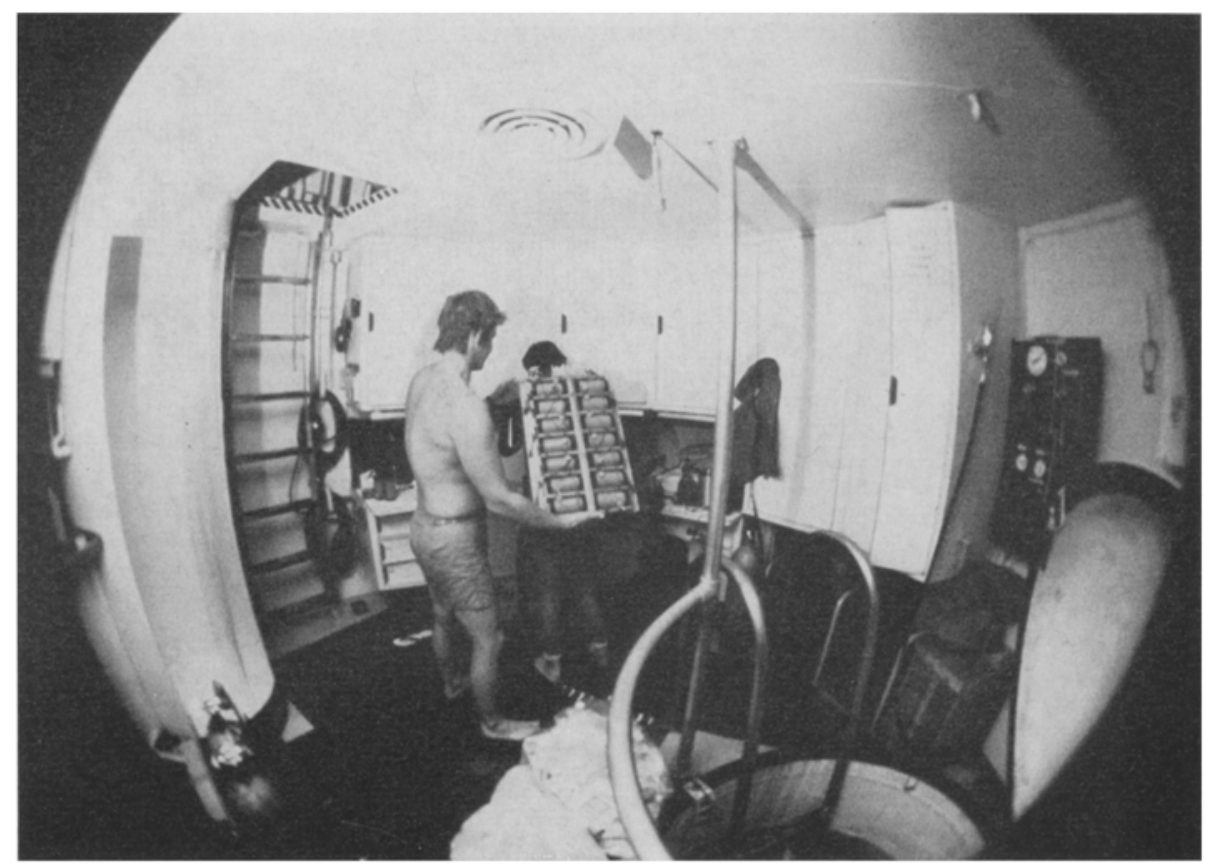

Fig. 4: Two aquanauts in the Tektite wet room prepare for an excursion. The relatively large space permitted up to four divers to suit up simultaneously. Other room features include a shower (left side), ladder to other compartments, scuba tank charging station (right side wall), and the entry trunk

blocked only a portion of the entry, thus allowing head space for a diver in the water. Four divers could comfortably rig gear and suit up simultaneously in the spacious Tektite wetroom.

The Hydro-Lab entry trunk also served as an entry pressure lock and was equipped with pressure hatches at either end. External and internal controls permitted pressurizing the lock from inside the habitat, inside the trunk, or outside the habitat.

The area immediately outside habitat entry trunks should be roomy and unobstructed. Good access to Tektites entry trunk was achieved via a spacious corridor at least 6 feet high within the habitat base. Access to Hydro-Lab's entry trunk was barely adequate because of pipe fittings projecting from the underlying base with only about 3 feet between the lower hatch and the base. A major disadvantage of the Hydro-Lab entry trunk was the need to use it as a dressing area. The first diver dressed had to go out into the water alone to await the second man who needed several minutes to don his gear (Fig. 5). The same problem existed upon returning 
from an excursion when the second diver, by then cold and tired, had to wait outside alone for the first man to clear the trunk. Edalhab's height above bottom was adjustable and during FLARE Mission I was excellent at about 8 feet above the sea bed (Fig. 6). This spacing of Edalhab and the concrete base of the Hydro-Lab solved

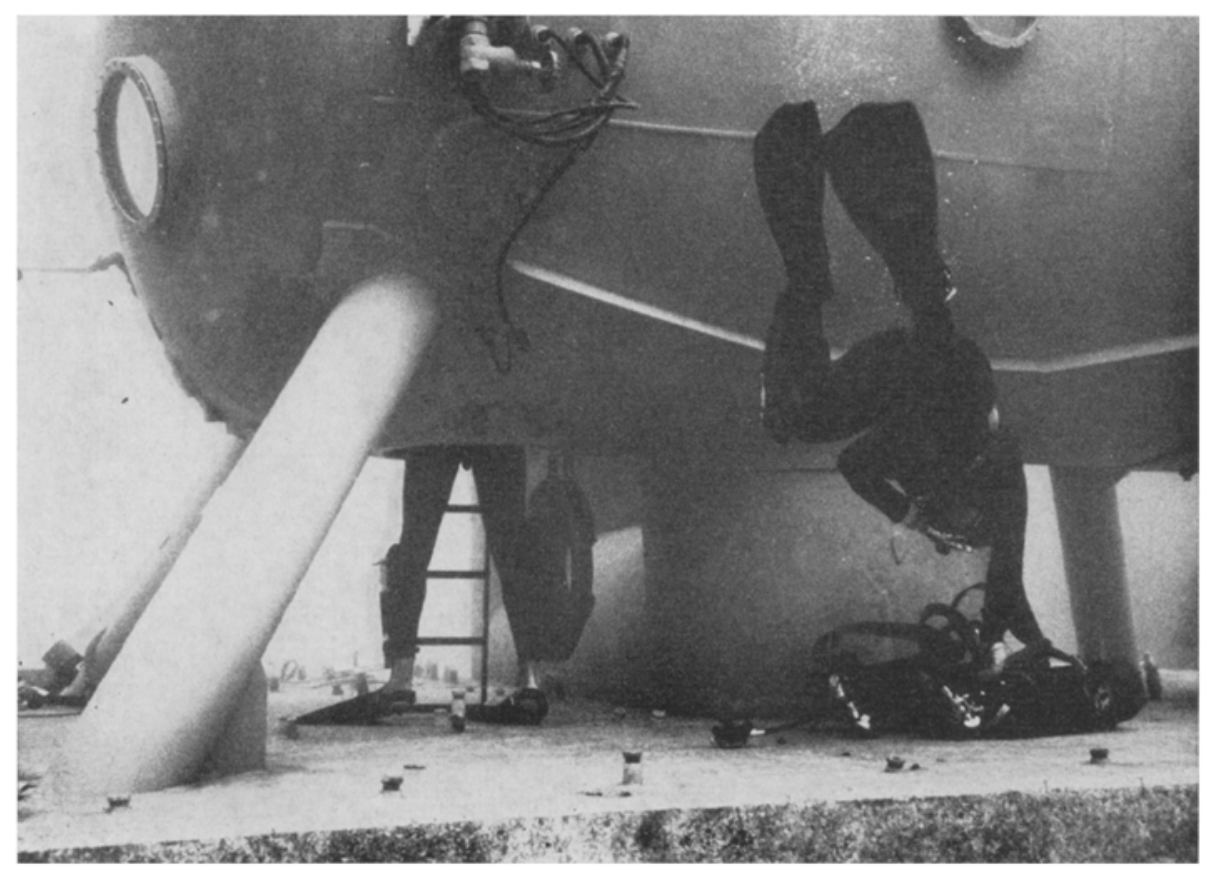

Fig. 5: Divers entering Hydro-Lab ditched their scuba tanks before passing up through the small entry trunk 3 feet above the concrete habitat base. Pipe fittings protruding up from the habitat base caused numerous painful minor injuries when team members inadvertently kneeled or stepped on them

the problem of a diver stirring up the sea floor when in the vicinity of the entry trunk. Large entry trunks such as those of Tektite and Edalhab were advantageous because two divers could come up together to talk and there would be adequate room to lift an inert diver into the habitat.

\section{External storage}

Aquanaut teams require storage space, not all of which need be inside the habitat. However, none of the three habitats included secure outside holding space. Because this deficiency was first noted at Tektite, we took large steel and brass snaps on later missions to hang cameras, tanks, sampling bags, etc., along the habitat sides. Low velocity water currents in the Virgin Islands allowed divers to leave most gear anywhere near the Tektite habitat. Currents were only slightly higher in the Bahamas. 
However, heavy surge during the Hydro-Lab mission caused by high seas sucked out wet suits stored in the entry trunk and carried away two empty scuba systems. Currents at the Edalhab Long Reef site in Florida exceeded $1 \frac{1}{4}$ knots at night and would have carried away unattached gear.

A narrow expanded metal rack beneath Edalhab adjacent to the entry trunk was provided for scuba storage. It was not convenient to use because of the low overhead. Regulators, pressure gauges, straps, and emergency equipment on the scuba units became entangled and were vulnerable to damage when moving them in and out of the rack. The aquanauts placed snaps on short lines along the habitat frame which permitted tanks to hang in midwater away from the steel structure and the sandy sea floor. Enclosed expanded metal cages would safely contain a wide variety of diver gear.

There was no suitable storage space for the breathing units and suits used by Hydro-Lab aquanauts. Consequently scuba gear lay in the sand near the entry. Surge and diver activity caused sand to frequently fill the regulators. Wet suits and other small items stored outside both small habitats were placed in mesh bags accessible by reaching out of the entry trunk.

If regulator changes are to be made underwater, a hood could be provided and supplied with air from the habitat discharge to keep tank valves out of the water during changes. Providing an air filling hose outside the habitat would eliminate the major support effort needed for tank filling at Hydro-Lab and Edalhab and would require less diver effort than at Tektite where to recharge tanks, aquanauts had to climb into the habitat fully equipped.

\section{Dry storage and work space}

Provision for dry storage of gear and supplies and for interior work space varied. Edalhab, although smallest of the three habitats, used the available space most effectively. Tektite, because of its large size, had ample room. In some cases, however, wall cabinets came too near the counter space, restricting the height of items that could be placed there. Dry storage space in Hydro-Lab was minimal. Therefore, equipment was scattered on the table, floor, or bunks because only a limited number of shelves, which were not convenient to reach, were located in the submarine lockout tunnel.

Wooden pegs along one Edalhab wall were handy for hanging towels, cameras, and other equipment. However, they constituted a potentially hazardous protrusion. The danger would be reduced if strings were fastened a few inches out, parallel to the wall, for hanging items.

At no time were all available desks or counter tops in use within Tektite. Although Edalhab's writing desk could not be used when the portable cot was up, a small counter was always clear. Both of these habitats provided suitable lighting for writing or other research activities. Where fixed facilities are not practical, chairs with writing arms or a desk top that folds down would be useful. Adequate lighting for desks is important. 


\section{Viewing ports}

Suitability of viewing ports varied greatly between the habitats. The large flat glass window in one end of Hydro-Lab provided a wide view of nearby reef areas. The several other small ports were rarely used because of their locations and limited views. Small flat glass ports at each end of the Edalhab cylinder were of little use. Excellent viewing was possible from Tektite because one or more hemispheric domes were conveniently situated in each compartment.

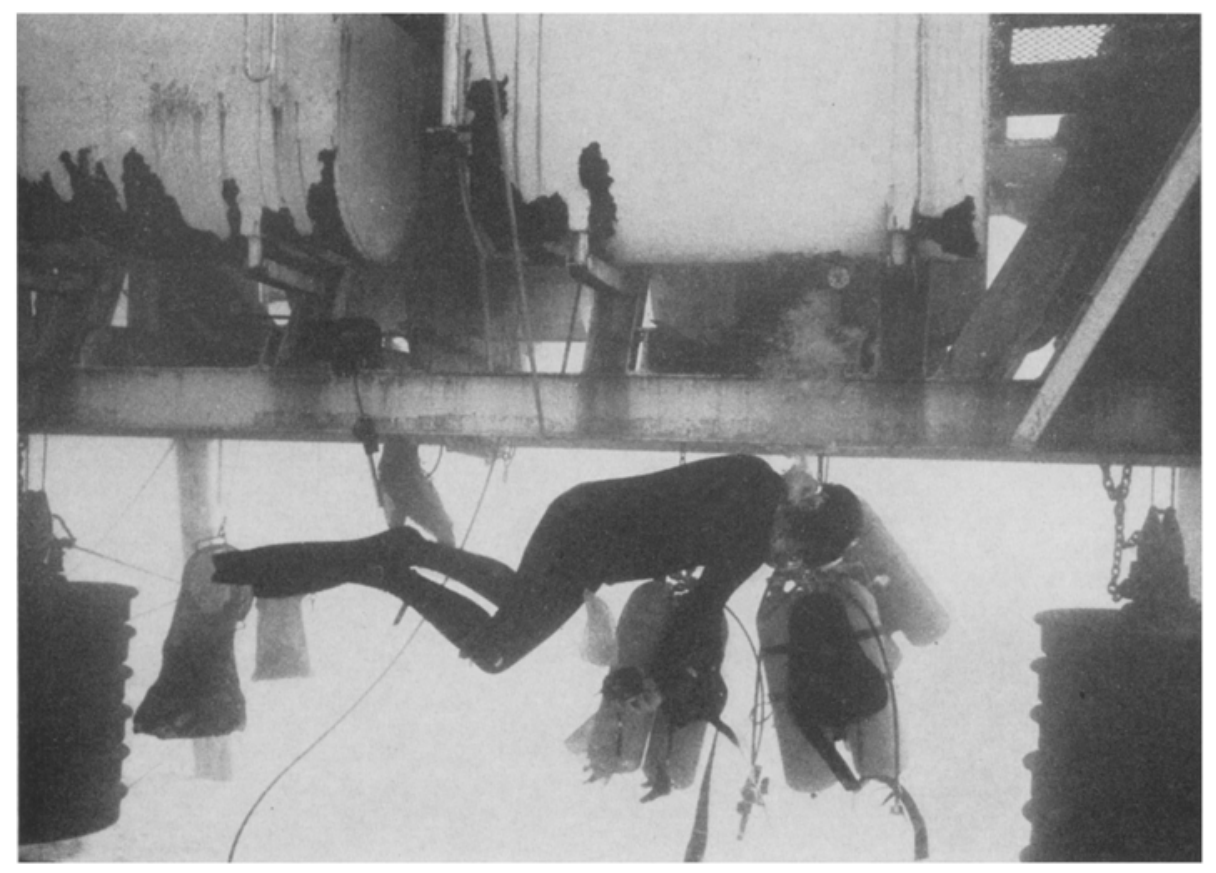

Fig. 6: Holding his breath, a diver swims down from the Edalhab entry trunk and dons his scuba system hanging beneath the habitat. Surface support divers returned empty cylinders to the surface for refilling

Habitat designers should consider viewing ports as potential research tools. Valuable observations were made while divers were confined in habitats having adequate ports. Hemispheric windows are preferable to flat windows because of the increased field of view. Observers should be located out of the habitat traffic patterns and able to sit or lie comfortably for long periods. Competition for the space develops when only a single window is available. The habitat must be deployed with care to assure the best view.

\section{Sanitary facilities}

A wash basin, shower, and toilet are considered important hygiene and personal comfort items for saturation dives, especially during extended missions. Only Hydro- 
Lab did not have a wash basin, yet the convenient location of its shower nozzle partly served that function.

Most aquanauts place a hot-water shower high on the list of desired habitat accessories. Tektite was equipped with a compact shower stall supplied with hot water even though fresh water was expensive and had to be trucked to the shore station (Fig. 4). A hand-held shower head was connected to a 250-gallon water supply

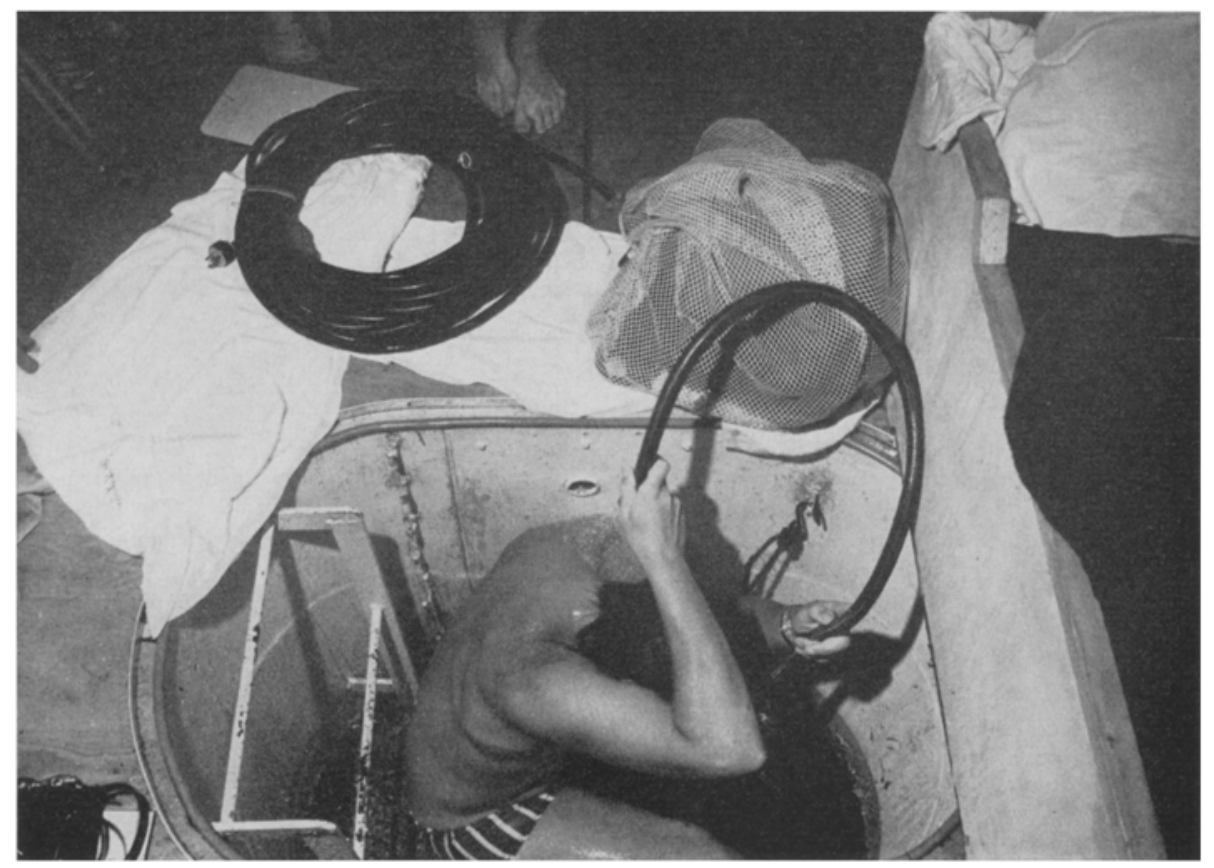

Fig. 7: A view from within Edalhab shows the limited arrangement for showers. The diver crouched on a movable platform slightly below the entry trunk water level. A carelessly directed hose occasionally sprayed the habitat interior with water

on the Hydro-Lab surface barge. Re-supply of the tank during the mission was inconvenient so strict water conservation was practiced. Since the water supply was not heated (ambient temperature was about $77^{\circ} \mathrm{F}$ ), there was no incentive to use large amounts. Edalhab aquanauts, like those at Hydro-Lab, crouched in the entry trunk to shower (Fig. 7). On request, a hose was lowered from the support ship after the team entered the facility. However, since each diver in turn had to stand in the trunk to remove his gear and delivery of the hose was frequently delayed, Mission I team members often reluctantly skipped the shower as not being worth the time delay.

Showers need not be elaborate. A simple curtained area to reduce splash in the wet room and a hand-held water sprayer is adequate. Divers need a rapid means of warming themselves after long exposure, even in 75 to $80^{\circ} \mathrm{F}$ water. 
An electric clothes dryer was provided in Tektite. Towels could be dried and reused several times. Damp towels left in the other habitats contributed to high humidity.

Tektite was equipped with a marine-type electric pump flushing toilet. A long discharge hose carried effluent from the toilet and sinks away from the habitat and research areas. Camp-style chemical toilets used in other habitats were inadequate. Often the divers relieved themselves in the water. This practice would not be possible in cold-water regions.

\section{Flooring}

The type of flooring used in a habitat is important and should be of good material. Although the uneven concrete slabs and plastic-covered grating in HydroLab provided a non-skid surface, they could not be satisfactorily dried, and barefoot aquanauts often stubbed their toes. The fiberglass-covered plywood floor in Edalhab was rough enough to provide traction and yet was comfortable to walk on with bare feet. Also, water was easily wiped up. Carpeting in wet areas retains water and promotes bacterial growth. However, it was comfortable in dry areas of Tektite. Smooth vinyls may be slippery and present a danger to the divers.

\section{Noise control}

Air entering and escaping is the greatest source of noise in habitats. The low volume of air exchanged was not irritating in Tektite, especially because it could only be heard escaping in the wet room. Both incoming and escaping air at HydroLab was disturbing. Every few seconds air would overflow out the entry trunk with a nerve-shattering bubbling roar. At night, a cover was placed over the entry trunk to dampen the sound.

A 2-inch diameter pipe, opening through the side of the Edalhab entry trunk several inches above its base, permitted air to escape with a more uniform rushing sound. An outlet of greater size should decrease the noise level of outflowing air. With the floor cover in place at night, the noise was not disturbing. A baffle on the Edalhab air inlet worked well to reduce sound.

\section{Food service}

Food provided for various Tektite teams was either unprepared, such as frozen meats, fresh vegetables, canned fruit, etc., or consisted of individually prepared servings on the order of airline meals stored in the habitat freezer (SMITH et al. 1971). The former was time-consuming to prepare using a conventional electric stove top and oven (Fig. 8). Many cooking containers and utensils were required. All team members had to be present at a pre-selected meal time. On the other hand, the airline-type prepared meals could be heated and served anytime to any number of 
people and eliminated need for cookware. Transporting frozen foods to the habitat did generate some problems because of the warm weather and isolated location.

Little attention was given to food service in Hydro-Lab because missions were short and space limited. In December 1971, meals for three Hydro-Lab residents

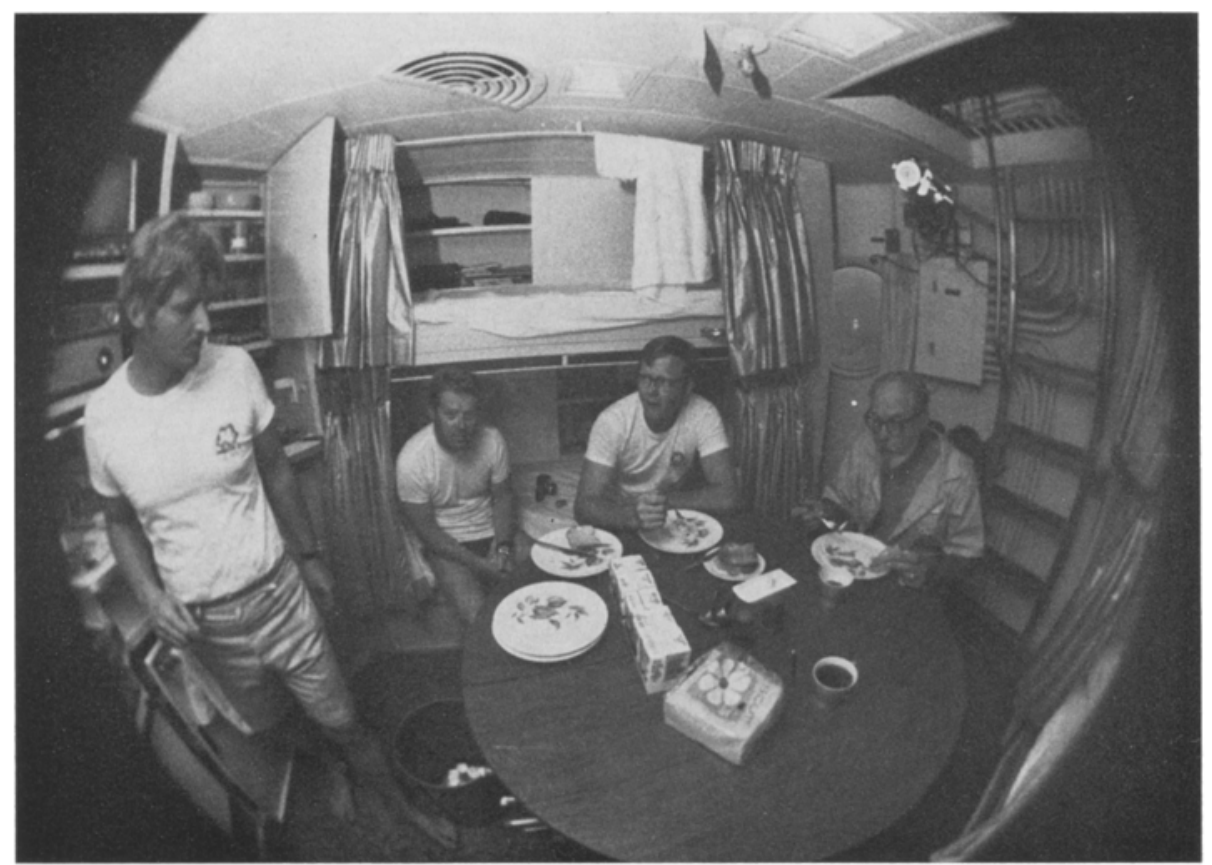

Fig. 8: Tektite aquanauts Richard Curry, William High, Alan Beardsley, and Ed Batutis enjoyed relatively luxurious accommodations, including a food preparation center and four bunks in the crew quarters, one of four habitat rooms. A television camera above the electrical wall panel and an open microphone hanging between the ceiling lights allowed support personnel to monitor the divers at all times

consisted of packets of freeze-dried food, designed for campers, reconstituted with hot water from a small electric coffee pot. Snack items included prepared sandwich spreads, bread, cookies, and candy; canned fruit and juices supplemented the meals. Although not particularly appetizing, the food was adequate for the 5-day mission. Importantly, each scientist had freedom to eat when he required food, and eating did not interfere with diving operations. Very little space was assigned for food preparation and storage. No refrigeration was available.

Edalhab had no provisions for food preparation. Fully prepared meals were delivered to the diving team in a watertight container. Unfortunately, meals were normally available during selected periods when meals also were being served to surface-support personnel aboard the R/V LULU. Thirty to forty minutes were needed to get delivery after team members requested food. As with preparing meals in Tektite, research schedules had to be altered to fit meal periods instead of having 
meals fit the research schedule as was done in Hydro-Lab and Tektite II when frozen prepared meals were supplied.

During short missions (about 6 days or less) food service should be simple since most scientists are prepared to "camp out". Frozen prepared meals heated in a compact microwave or similar oven provide the solution for extended missions. Refrigeration in either case is desirable.

\section{Sleeping accommodations}

Adequate sleep is a prerequisite to physical and mental fitness. Often aquanauts devote full time to their work with minimum sleep, and they do not engage in normal breaks for leisure. Bunks therefore must permit restful sleep. Proper habitat temperature and humidity control contribute to sleeping comfort. Tektite bunks and en-

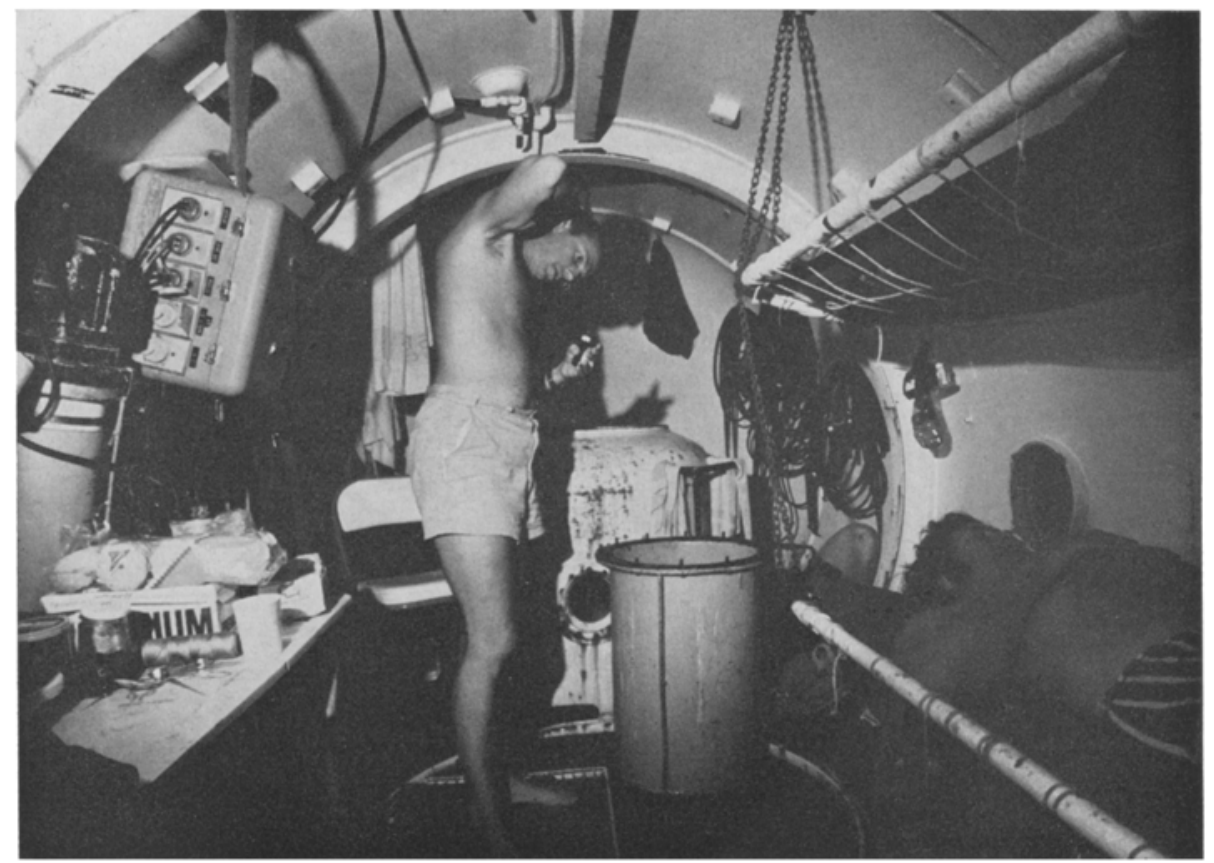

Fig. 9: Inside Hydro-Lab, lan Ellis sleeps while William Schroeder flushes his ear with an alcohol solution to reduce the likclihood of fungus infection. Note the large opened dry transfer pot which had to be hoisted with block and tackle in and out of the habitat

vironment were ideal (Fig. 8). Open celled foam mattresses remained soft whereas the closed celled material used in Edalhab bunks compressed and was extremely hard.

Minor repairs would make the air mattress covered bunks in Hydro-Lab acceptable (Fig. 9). However, other conditions made restful sleep difficult. The noise level has been discussed elsewhere as well as the requirement for divers to stand watches. 
The diver on watch usually had the light on and every 30 minutes he called the shore station by radio; both conditions disturbed the sleep of the off-duty diver. Since there were only two bunks, all three team members could not take a short nap between excursions.

A permanently assigned bunk for each aquanaut is important. It should be rigged for use anytime. During long missions, a light is needed for each bunk and an earphone for music. In the small habitats divers usually lie in their bunk to get out of the way when others are working or moving about.

\section{Support features}

Equally important to the habitats are the various support systems. The support features discussed here - decompression, diver air supplies, and equipment transfer-differed somewhat for each saturation diving program.

\section{Decompression procedures}

Hydro-Lab was designed to function both as an undersea laboratory and a decompression chamber. At mission's end, the aquanauts sealed the entry trunk and

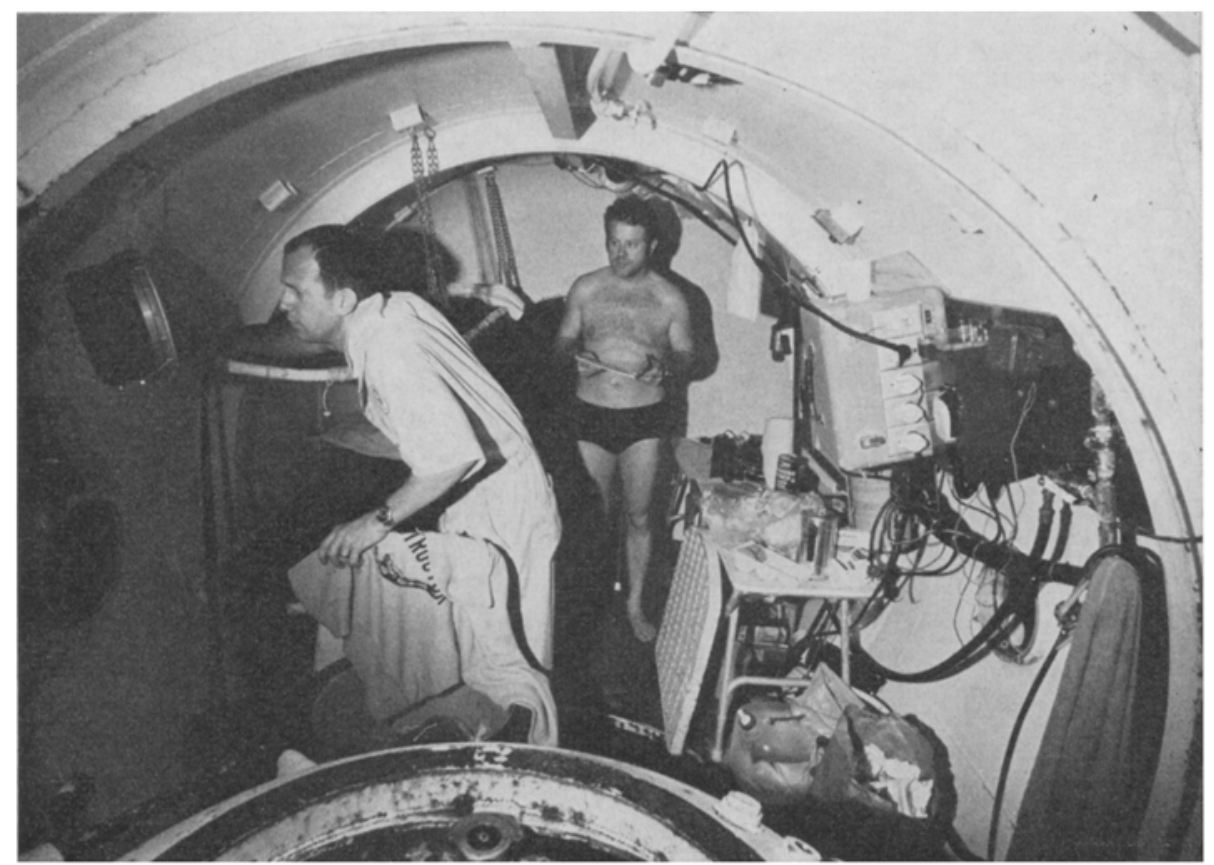

Fig. 10: Aquanauts William Schroeder and William High monitor internal pressure change while they carry out a 14 -hour decompression schedule from within Hydro-Lab 


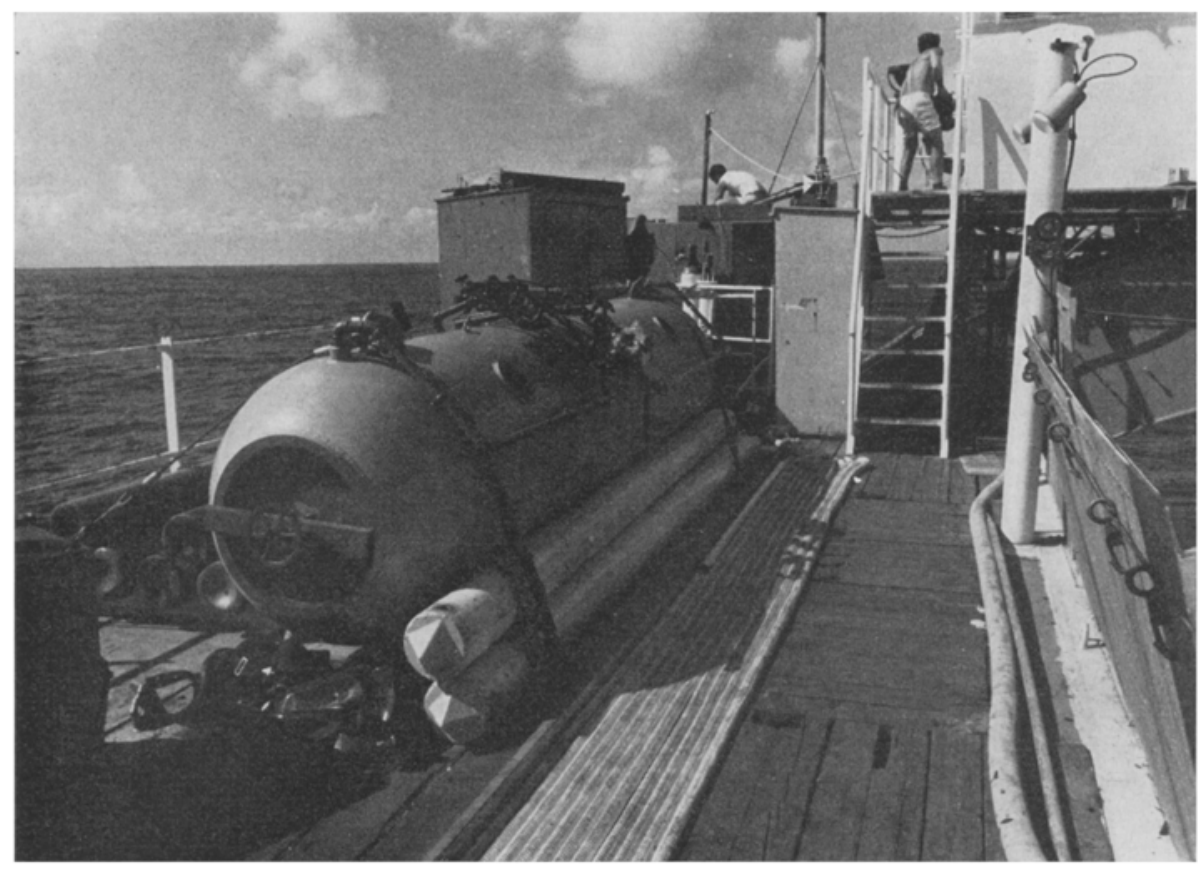

Fig. 11: After swimming from Edalhab to the surface. FLARE aquanauts were quickly repressurized in this small, two-lock chamber, Absence of air conditioning and space for the team to lie down made the 20-hour stay unpleasant

decompressed themselves (Fig. 10). Compared to the Tektite and Edalhab procedures, this was excellent. The divers continued observations from the viewing port, the habitat remained cool, and all habitat accommodations were available to them. Nearly 7 hours less decompression time was required by Hydro-Lab divers than those in Edalhab (13 versus $19 \mathrm{hr}$ ) although depth, duration, and type of gas were similar. It is noteworthy that an earlier two-man team decompressed from a HydroLab saturation dive in a similar depth in less than 4 hours, indicating some reduction of decompression time is possible.

The deck decompression chamber (DDC) and personnel transfer chamber (PTC) system for decompressing Tektite II aquanauts was the largest and most elaborate system. The DDC was equal in size to Edalhab. Unfortunately, the air conditioner did not work during early missions, causing an uncomfortably high inside temperature. The cost of equipment and operation was much higher than the other systems described.

The decompression procedure for Edalhab divers was unique. To reach the DDC, team members swam quickly to the surface, boarded the surface support ship, R/V LULU, and were repressurized in the chamber within about 2 minutes (Fig. 11). Although this method worked successfully there may be some additional risk, and the method cannot be used when divers are working at greater depths. The two-lock, 
$31 / 2-\mathrm{ft}$ diameter by $11-\mathrm{ft}$ long chamber was grossly inadequate for long decompression. Divers could neither stand nor lie comfortably in a prone position. Without air conditioning, the temperature remained high during daylight hours even though a canvas cover was installed for shade and water was sprayed over the chamber.

During 'Tektite and Hydro-Lab decompression, the aquanauts encountered breathing discomfort using the oxygen masks. Noticeable effort was required to draw and expel oxygen through the masks. Chest pains developed similar to those experienced by a diver who breaths through a snorkle for long periods. Dehydration, caused by the very dry oxygen, was also a problem. Oxygen masks used in Edalhab prior to the diver's departure for the decompression chamber were very comfortable.

\section{Diver air systems}

Open-circuit scuba was the primary source of air for divers working from the three habitats discussed in this report. However, during each program the actual arrangement of tanks, regulators, and other components varied.

Tektite divers used two standard 71.2 cubic $\mathrm{ft}$ capacity cylinders fitted to a typical double-tank contoured backpack. Each tank had a "J" reserve (low air warning device) and single-hose regulator attached. During early missions only the left side regulator included a direct reading pressure gauge. Air reserves of both tanks were used; air from the right tank was consumed down to its reserve, then the left side tank and regulator were used. Air consumption on the left tank was monitored with the pressure gauge. The left reserve served as a low air reminder in case a diver failed to watch his gauge closely. The small amount of air remaining in the right cylinder provided emergency air in the event of an equipment failure on the left side or it could be used by another diver. By Mission 4-50 the sequence of tank use was reversed because direct reading gauges were supplied for both regulators. Divers began by breathing the left tank down to its reserve. They checked the reserve to assure its proper operation, then switched to the right side cylinder. Pressure gauges gave a continuous readout of remaining air in each tank, and both reserves were held for emergency breathing. Surface safety boats were equipped with extra air tanks, and personnel could reach the divers within 1 or 2 minutes after an emergency signal. This system provided complete breathing equipment redundancy.

Double, open-circuit scuba-tank systems were also used by Hydro-Lab divers. The tanks were joined by a manifold to which an octopus regulator was attached. The octopus regulator consisted of two second stage, single hose regulators and a direct reading pressure gauge connected to a regulator first stage and yoke. Unfortunately, this system provided only partial redundancy. A failure of the first stage would have caused the system to fail. Although no problems occurred during saturation dives, one diver had a regulator first-stage malfunction which rendered his unit useless during diving activities prior to the FLARE Mission.

Edalhab divers were provided standard double cylinders manifolded to a single valve and "J" reserve. A direct-reading pressure gauge was attached to a singlehose regulator. A small, 22-cubic $\mathrm{ft}$ capacity cylinder (commonly called a pony bottle) 
with a " $K$ " valve and single-hose regulator was clamped between the large double tanks to serve as an emergency unit. A near accident occurred during FLARE Mission I when a diver inadvertently began an excursion breathing from the pony bottle because he could not distinguish between the main and pony-bottle regulator. The systems used at Tektite and Edalhab appear to be the safest. Obviously, steps must be taken to assure ready identification of the pony-bottle regulator.

General Electric (GE) Mark 10\% rebreathers were used by some teams during Tektite II. Rebreathers gave the scientist/aquanaut two distinct advantages over open circuit scuba: (1) they allowed continuous diving for up to 4 hours by eliminating the necessity to return to the habitat and recharge air cylinders and (2) their low noise level and lack of bubbles allowed the aquanaut to approach marine life very closely without interfering with the normal behavior patterns of the organisms. During a bioacoustical study, the investigators were able to detect with the unaided ear both background noises and the sounds produced by fishes and certain invertebrates. A later model GE rebreather greatly simplified the pre- and post-dive procedures which the aquanauts were required to perform on each unit for every dive. During the first few missions as much as $1 / 2$ to 2 hours were needed for this procedure. The time was reduced to $1 / 2$ to 1 hour in later missions using the newer model. Regardless of the time involved for the pre- and post-dive procedure, the advantages gained by using the rebreathers compensated for this time loss.

Additional training of approximately 3 to 4 days was required for each aquanaut before his mission to qualify to use the rebreathers. For long saturation missions (14 days or more) this training time is a small investment. However, if duration of the saturation mission is only 5 to 6 days, the time required for premission preparation and training could exceed the saturation time. Careful planning is called for when making the decision as to whether advanced diving systems such as the rebreather should be utilized.

Safety features incorporated into the rebreathers included the ability to manually operate the unit in the event of a power loss, and a compressed air pony bottle equipped with a standard single hose scuba regulator was strapped to the rebreather shell.

Hookah-rigged full face masks were available for use at Hydro-Lab. However, the hookah system is not generally well suited for use on coral reefs because the long hoses hang up frequently. Strong currents also hindered free diver movement and hose recovery. A backup system such as the pony bottle or octopus regulator should be incorporated into hookah systems because a full mask eliminates sharing air in an emergency.

Boats were not restricted from the surface near Hydro-Lab. Anchoring vessels might have snagged the hookah hose and pulled it loose or dragged the saturated diver to the surface. Both wet and dry submarines operating in the immediate area were also a potential danger to the aquanauts had they been using air hoses.

* Trade names referred to in this publication do not imply endorsement of commercial products by the National Marine Fisheries Service. 


\section{Dry pot transfer system}

Once an undersea laboratory has been placed upon the sea floor, all water sensitive items must be moved in or out of the habitat within a watertight, pressureproof container. The container (pot) size often dictates what research instruments are available for use unless the instruments are installed prior to sinking the habitat.

Acceptable pot size is dependent upon both physical dimensions of the habitat entry trunk and the ability of surface support personnel and aquanauts to handle it Often, transfer pots were modified pressure paint spray cans. None of the habitat programs mentioned here had an efficient or reliable pot system. All pots used leaked occasionally; consequently, scientists hesitated to bring some valuable equipment into the habitat. Support divers had difficulty handling pots because buoyancy changed depending upon their contents. It was difficult for two divers to lint the Tektite pot by hand from the entry trunk because no block and tackle was available for the first few missions. Two men readily raised the Hydro-Lab pot with block and tackle, but the pot was too long to properly clear the trunk once inside. There was danger of dropping the pot on an aquanaut's bare feet (Fig. 9).

The Edalhab pot was made from a large home pressure cooker. It flooded when meals were transferred to the team because it was designed to retain internal pressure but not withstand external pressure. A pressure fitting, installed so internal pressure could be raised above ambient, stopped the leak. Few pot transfers were made into Edalhab because between missions, when the habitat was raised to the surface, an 18-inch diameter top hatch was opened for free entry (Fig. 2).

Pots for both Telstite II and Hydro-Lab were carried down by surface support divers. The weighted Edalhab pot was lowered by a rope to the sand adjacent to the habitat, then the aquanauts pulled it in. Strong water currents often caused the pot to hang up on the habitat or entry ladder. Because of its weight, it was very difficult to lift up out of the trunk. Fortunately it usually remained in an upright position so the plates of food were not spilled.

All items placed in the transfer pots were first sealed in plastic bags. Thereafter, even serious leakage failed to dampen the contents. The Hydro-Lab system would be greatly improved if the block and tackle were made from materials unaffected by salt water. Also, it should not be necessary to lift the pot into the habitat from the entry trunk. A quick-opening lid instead of the numerous bolts usually used would permit convenient equipment transfer while the pot remained on the block and tackle in the entry trunk. However, since it would block the exit, it could not be stored there and should be quickly removable in the event of emergency during transfer operations.

\section{Accessory features}

Not all accessory features used by the aquanauts are discussed here, but underwater lights and cameras were used by nearly every diver and required special consideration. In addition, we have some comments on diver propulsion units. 


\section{Underwater lights}

Considerable saturation diving takes place during hours of darkness, as reported by TenNeY (1971) from his observations during the Tektite II program. Hand-held, pressuremproof lights are required for both emergency habitat lighting and when making excursions. Several specially marked lights should be strategically located both inside and outside the habitat and reserved for emergency use.

Rechargeable wide and narrow beam lights seem the best if they are reliable and can be recharged in the habitat. Scientists with the Tektite program were prohibited from using any electrical item not especially equipped with ground wires so underwater lights were sent to the surface for recharging.

Several problems were encountered with underwater lights in the three habitat programs. On one occasion a diver inadvertently released his hand-held light which was not equipped with a lanyard. The light floated to the surface and began drifting away in heavy seas and a strong current. The support divers, fearing a diver was in trouble, chased and eventually recovered the light. Unfortunately, the incident resulted in cancellation of diving for the night. On other occasions, rechargeable and ordinary battery-operated lights failed during excursions due to short circuiting or flooding.

All habitats discussed here were equipped with one or more high output lights attached to the habitat exterior. At Tektite, one lamp was connected to a long electrical cord so it could be carried some distance from the habitat. This was very useful and at least one such lamp with 250 feet of electrical cord should be provided for any habitat with provisions for additional lights if needed during special studies. Light fixtures mounted on the habitat should rotate.

The single Hydro-Lab exterior lamp had to be extinguished at intervals to prevent overheating the wires. This was a potential hazard and should be corrected so the lamp can remain lit indefinitely. Bulb replacement on the Hydro-Lab light necessitated loosening the through-hull stuffing box on top of the habitat and pulling out the wire. A cork stuffed into the opening prevented habitat pressure loss while the fixture was taken to the surface. Lamps should have underwater connectors and all through-hull penetrators should pass out the habitat bottom.

Aquanauts have a tendency to rely on the habitat lights as a homing beacon at night. The lamps should not replace other methods for finding the habitat. A sudden power loss, such as occasionally occurred at Tektite II, requires the divers to find another way to locate the habitat.

\section{Cameras}

Some scientists will find use for a portable underwater television camera which has sufficient electrical cord to move it to study areas near the habitat. Caution must be exercised with all television cameras, including those inside the habitat to prevent burning the vidicon tube with flashes from bulbs or camera-electronic strobe lights. Before flash pictures are taken, monitoring cameras should be turned off or capped. 
Opening an underwater camera in the habitat is impossible unless the internal pressure of the camera is the same as the habitat. This requires that the camera be equipped with a pressure-equalizing fitting or be brought into the habitat disassembled in a dry transfer pot. Once the camera interior has been equalized, film changes can be made routinely. Too frequently, aquanauts fail to realize they must not carry a habitatequalized camera into less water depth than the entry trunk. Overpressure, developed within the camera at reduced depth, breaks the " $O$ " ring seals and may cause the camera to flood. Since this concern is contrary to normal diver practice, aquanauts often forget and swim up to take photographs of the side or top of the habitat or shallow reefs.

\section{Diver propulsion units}

Diver propulsion units provide the potential to extend diver operating range, simplify movement, or increase the gear carried by a diver. However, many aquanauts believe saturated divers should not go beyond the point from which they can return to the habitat without the swimming aid. Equipment failures causd by electrical shorts, flooding, or power loss from overuse are common enough to rightfully question their reliability.

Propulsion units readily available to divers have limited endurance when compared to the aquanaut's extended excursion time. Numerous batteries should be available to keep the units functional through an aquanaut's typical day.

Aquanauts were invited to ride as passangers in two wet submersibles during the Hydro-Lab dive. As a passenger, the aquanaut had poor communication with the pilot and no control over where the submersible went. Saturated divers should not go into new areas away from the habitat without good bearings to return home.

A small hand-operated diver propulsion unit was successfully used during the Hydro-Lab mission as a research aid. Two plankton nets attached to the unit were guided over the reef to collect selected samples (Fig. 12). Similar propulsion units were used by some FLARE aquanaut teams.

\section{Operations}

Surface support is vital to successful saturation dives. Personnel must function efficiently to provide aquanauts with equipment and time to carry out research goals. Each operational task taken out of the hands of the scientist enhances his ability to perform.

\section{Surface expeditor}

Aquanauts occasionally encountered difficulty obtaining assistance from support personnel to repair equipment or purchase new parts. Surface staff were usually fully committed to their special tasks and could not readily handle the scientists' requests.

During the Hydro-Lab mission the response was usually good. However, requests were limited due to the unfamiliarity of surface personnel with the mission's ob- 


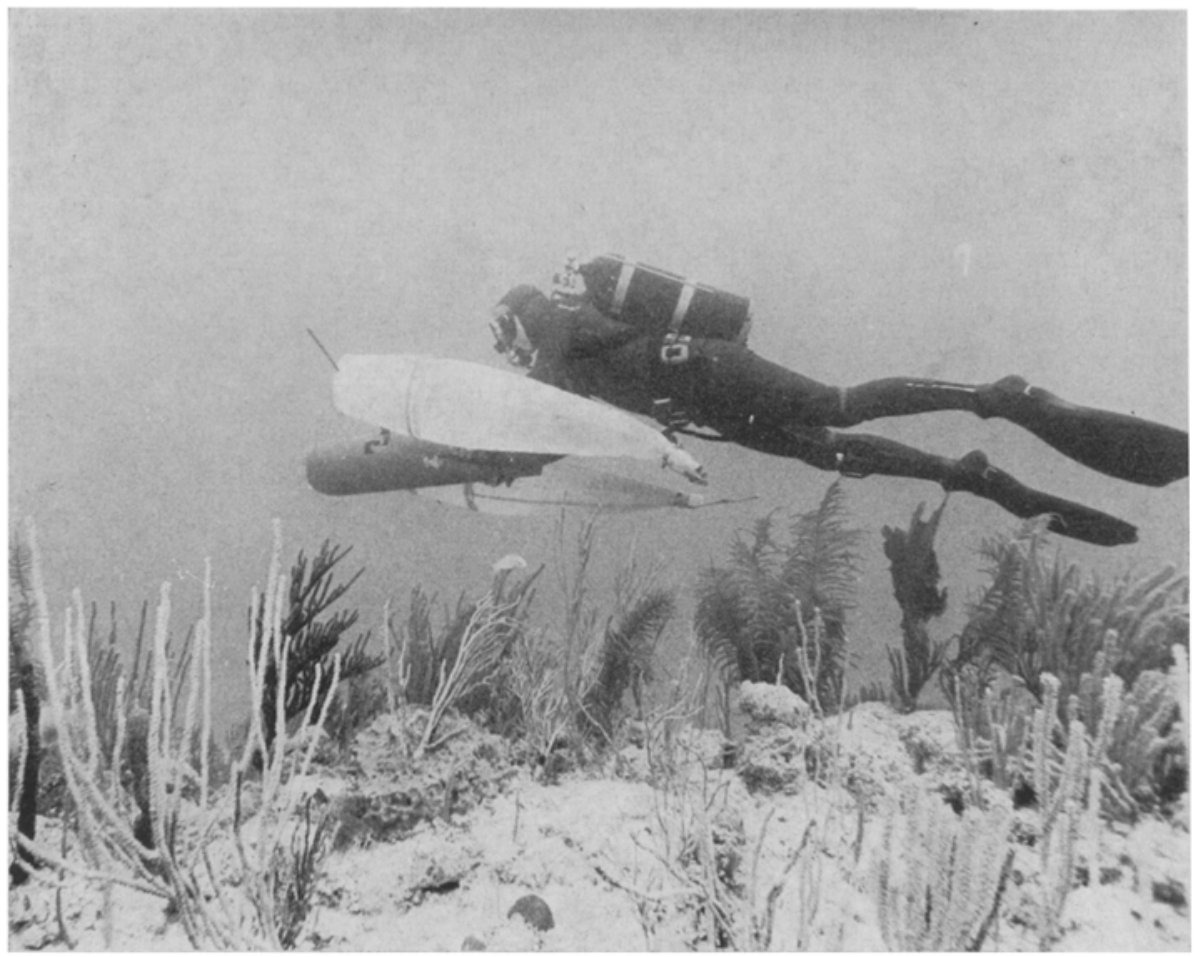

Fig. 12: Some aquanauts used diver propulsion units to reduce swimming exertion in currents and to tow sampling nets along precise routes

jectives and equipment. Early in the FLARE program there was some difficulty in the aquanaut-to-surface communication chain and non-compliance with some requests limited excursion time and made attainment of scientific objectives difficult.

Future habitat programs should include for each scientific mission, a topside representative of the scientific party who is thoroughly familiar with their equipment, objectives, and methods. This individual should be a member of the scientific party and not a member of the support staff or vessel crew. The individual should be thoroughly familiar with where all equipment is stored, how they operate, details of repair, availability of desired services, spare food, etc. This individual's sole responsibility during the mission should be to supply equipment as needed by the aquanauts and to arrange and expedite special requests for them.

\section{Watch standing}

A different method was employed in ead habitat to monitor the life support system and the aquanauts during night sleeping periods. As shoreside watch personnel at Tektite were able to monitor oxygen level and rate of air flow to the habitat on 
closed circuit television and visually monitor two of the four rooms (engine and wet rooms remained lighted at all times), all divers were permitted to sleep at the same time. Open microphones in each room were also monitored at the control center.

Hydro-Lab support personnel maintained radio contact with the divers. From 8:00 PM to 8:00 AM one diver was required to remain awake in the habitat and communicate with a surface support watchkeeper every 30 minutes; consequently only two bunks were provided. Lack of an independent monitoring system was a disadvantage because team members did not get adequate undisturbed sleep.

One diver was required to remain in Tektite and Hydro-Lab at all times to maintain surface contact and monitor habitat systems. This was usually done by the Tektite engineer; thus the remaining scientists were free to leave whenever their work required. However, this requirement reduced water-work time for each Hydro-Lab scientist by several hours each day as they stood their habitat watch.

Watch standing by team members at FLARE was eliminated because all system monitoring was carried out by surface personnel. A closed circuit television camera permitted the habitat interior to be viewed at all times. At night one team member strapped to himself a heart-rate radio transmitter which was monitored at the surface control center, thereby allowing all team members to sleep.

\section{Communications}

Voice communications between habitat occupants and the surface-watch director posed many problems. Messages from the aquanauts to support leaders relayed through a watch director often didn't arrive in their original form.

Although Hydro-Lab had the least sophisticated system, a simple citizens band radio, results were most consistent. Usually the expeditor was called to the radio and he personally took the message.

Surface personnel want to be well informed about the aquanauts' activity and excursion plans. However, it becomes frustrating for scientists to delay their work for extended communication sessions. Both Tektite and Edalhab were equipped with closed circuit television to monitor diver activities and habitat status. Careful attention to the monitor by an experienced watch director should eliminate many questions which arise. Open microphones (as used in Tektite) permitted the surface personnel to follow diver conversation and planning and, importantly, eliminated need for a diver team member to station himself near the communications console.

Frequently, aquanauts wanted to talk to the watch director after they began an excursion. It was difficult to enter Tektite and Edalhab in full gear, reach the surface communication system, and report. When frequent communications between surface personnel and divers are desired, an open microphone should be placed in the entry trunk so divers need not leave the water.

Excellent voice contact is available between divers and a surface station when using recently developed underwater communication systems. The authors used one system during Hydro-Lab operations to communicate between a team member in the water and the one stationed in the habitat. Unfamiliarity with the equipment and problems with early models limited the use of this potentially valuable gear. 


\section{Safety}

Safety programs for saturation diving are necessarily complex and are further complicated by the limited experience of some aquanauts. Certain procedures, equipment, and training can improve the aquanauts'safety and confidence.

Some conventional diver-safety gear may actually create a hazard. Aquanauts using weight belts do not want them to release too easily. Buoyancy control vests should not have inflation cartridges that may activate accidently.

\section{Surface safety divers}

The role of surface-based safety divers is variable and dependent upon program goals. Surface-safety divers were both an asset and limiting factor to the orderly progress of the aquanauts' research. Surface divers were on call 24 hours per day at both Tektite and Edalhab and they actively monitored the location of swimming aquanauts. Whenever safety divers were involved in other duties, aquanauts could not leave the habitat.

Whenever aquanauts left the immediate vicinity of Tektite, a small boat carrying an operator, diver, and extra air cylinders followed. Preplanned travel routes allowed the boat to remain near the underwater team even in rough seas when bubbles were lost or when closed-circuit breathing units were used. During Edalhab missions, a watch was maintained by the two on-duty divers from the surface support vessel, $\mathrm{R} / \mathrm{V}$ LULU. Their diving gear had been loaded in a skiff in the event the saturated diving team signaled for assistance.

It was often difficult for the aquanauts to pre-plan their excursion route in enough detail to satisfy surface personnel requests. During the FLARE program the authors preferred to remain in the water for long periods. Air cylinders were changed when necessary and work continued without re-entering the habitat repeatedly to update route plans. The nature of the research did not lend itself to total pre-planning. Aquanauts were occasionally restricted to the Tektite and Edalhab habitats because safety divers were temporarily assigned other duties and therefore were not available to monitor them.

No surface-safety divers were utilized at Hydro-Lab. Because the habitat and its automated surface supply barge lay over a mile from shore, the saturated diving team was without rapid surface aid. One team member remained inside the habitat at all times to maintain radio contact with the shore station. Team members were more apprehensive about making long excursions from the habitat than when safety personnel were near. Surface personnel visited the Hydro-Lab site several times a day to replenish air cylinders. Although operating costs are less when safety divers are excluded, certain alternate safety steps should then be taken, including well-defined underwater trails, air supplies available away from the habitat, and surface signal systems. 


\section{Underwater position markers}

Becoming lost during an excursion is a major concern, particularly when diving without surface-support divers. Assessment of bottom topography, depth change, and prevailing currents, the usual diver aids for underwater navigation, cannot be totally relied upon. Underwater compasses are valuable but should not replace other methods to orient the divers. Directional acoustic receivers have been used by divers seeking their habitat and support personnel searching for divers. However, experience shows that both transmitters and receivers can fail, be lost, or carelessly left behind.

The most positive means to aid an aquanaut is to lay stout string trails across the bottom. Strings radiating out from the habitat like spokes on a wheel will be found after only a short circular swim. In clear water areas, such as the Virgin Islands, Bahamas, and Florida, the line can be seen for some distance. In addition, small numbered floats attached by $15-\mathrm{ft}$ strings to the sea floor help establish location in relation to the habitat.

When considering the use of "string highways", planning must include some type of surface-buoy system which delineates the underwater marked area and prevents anchoring of surface craft and fishing within the area. Otherwise the trails may be snagged and accidently pulled loose.

\section{Emergency way stations}

An aquanaut's confidence drops as distance from the habitat increases. Both confidence and underwater safety would be enhanced if emergency air supplies were available in "way stations" along main travel routes. Plastic domes provided air trapping space in three shark cages placed along the reef near Tektite. Their large size allowed two divers to enter and talk when enough air from their open-circuit breathing units was released to displace the water. Program planners believed that the air would contaminate quickly if left after use so a vent on top of each dome was required to be opened whenever divers left the cage. Since no air was stored at the cage, divers seldom were willing to expend a significant portion of their air supply just to fill the dome to talk. Domes are usable by divers equipped with re-breathing units only if a compressed air supply is available.

A small air-filled plastic dome was tied by four lines 5 feet above the HydroLab base. It was intended as a dry space so regulators could be changed from empty tanks to full ones. However, divers found two double-tank units difficult to handle so the unattached regulator was frequently immersed. While changing regulators, the diver frequently released fresh air into the dome for breathing. Conversation was not possible as only one diver could enter the dome. A single way station was set about 200 feet from the habitat. Two divers could crouch beneath the steel hood for conversation, but no emergency air was provided.

Several large plastic domes provided for the FLARE project were stored aboard the surface-support ship and not set during Mission I.

Emergency air stations should be situated in strategic areas frequented by aquanauts. Desirable features would include air space for two fully equipped saturation 
divers, ready-to-use emergency air supply for at least two divers, a voice-communication system to the surface or habitat, and a surface-signaling device possibly composed of a tethered float releasable to the surface with a flashing strobe-light for night and a smoke flare for day use. An electronic distress-signal would alert surface personnel out of view of the water surface.

\section{Emergency signal gear}

Aquanauts working below surface-safety divers were provided with three methods to signal for emergency assistance - acoustic pingers, floats, and flashing lights. Each diver carried an acoustic pinger that could be detected at the support station when actuated. Rescue divers were equipped with directional receivers to "home in" on the distressed diver. The equipment was not reliable but this system remains a potentially useful distress signal system.

Each Tektite aquanaut was provided with a $\mathrm{CO}_{2}$ inflatable buoy. The bright yellow float was readily seen by safety divers when released. However, it did not mark the aquanaut's position for long because wind and current quickly carried it away. Eventually most aquanauts attached a coil of string to their signal floats. Although strings were attached to each float used during FLARE, in an emergency two lines failed to deploy properly and the drifting floats led safety divers away from the distressed aquanaut team.

Small electronic strobe flashing lights were provided for each diver; they were intended to pinpoint an aquanaut at night. However, at least one was placed on the surface signal float so the float would be seen if actuated at night.

The trouble frequently encountered with basically good safety gear emphasizes the need for gear engineered specifically for saturation divers.

\section{Aquanaut training requirements}

High standards of physical fitness and diving experience were not uniformly applied to all Tektite II aquanauts. Consequently, personnel with a wide range of experience were included in the program. Most teams were required to demonstrate several underwater skills and show composure above and below the surface during pre-mission dives. A few scientists arrived at the dive site without adequate training or were in poor physical condition. Fitness usually improved with numerous mission preparation dives. It was generally recognized that diving experience résumés prepared by candidates, although documenting impressive diving histories, could not be used as the sole qualification measure. Therefore, some system should be developed by which potential aquanauts could be tested, or upgrade their skill, well in advance of a mission.

The Hydro-Lab program director evaluated both diver qualifications and merits of research proposals for scientists seeking use of the habitat. One objective of the Hydro-Lab dive was to consider the type of training needed for saturation diving. Team members conducted strenuous swimming and diving workouts for several weeks 
prior to the dive. The program director made numerous dives with the team before commencing the saturation dive.

During selection of FLARE scientific proposals, consideration was given to documented qualifications of team leaders. The diving safety officer established a watermanship examination for aquanauts upon their arrival at the Edalhab site. Conventional diver skills were evaluated, including distance swimming, buddy breathing, diver rescue procedures, and underwater gear manipulation.

Experience gathered during Tektite, Hydro-Lab, and Edalhab missions now permits safety personnel to establish guidelines for aquanaut experience, pre-dive training, and testing.

Aquanaut training standards must insure that the diving scientist is a liability neither to himself nor to his teammates. They should be designed in such a way as to constructively point out both an aquanaut's weak and strong points. They should be confidence-building exercises as well as prerequisites. The novice aquanaut usually cannot fully appreciate the unique situations he will encounter routinely during a saturation dive. Few divers had carried out a scuba ditch and recovery in open water after leaving their basic diver training. Each Hydro-Lab and Edalhab scientist did it several times every day. Preferably, one team member should have previous saturation experience. All team members should dive together many times before commencing a saturation dive. Although it is difficult to directly relate diver capability with number of dives, it is unlikely that a diver having less than 50 dives over a wide range of conditions would be well prepared, especially to work from a habitat without surface support.

Even an active diver should participate in a fitness program for a month or more before a saturation dive. The authors found swimming with mask, fins, and snorkle 1/2 to 1 mile per session several times a week improved endurance.

An aquanaut candidate should be able to complete easily the following skills: (1) 800-yard scuba swim using a full complement of diving gear and double tanks. (2) Buddy-breathe 200 yards ("victim" without mask), switch roles, and continue another 200 yards. (3) On a single breath, swim 25 feet to a depth of 15 feet, turn on air, and don double scuba tanks. (4) Demonstrate easy handling of double scuba tanks in and out of the water. (5) Swim 100 yards, breathing from a regulator having rubber mouthpiece and non-return valves removed. (6) Tow an inert diver 100 yards. (7) Swim without aids in 14 minutes or less, 400 yards while alternating between at least three strokes.

\section{Tips for prospective aquanauts}

Even experienced scuba divers have difficulty anticipating all factors relevent to saturation diving. A number of valuable points are listed below as a guide for the novice aquanaut.

(1) Some aquanauts found the scuba mouthpiece difficult to hold after 2 or 3 days because of gum irritation from using the regulator for long periods. Gums can be toughened prior to the dive by holding a scuba rubber mouthpiece (removed from a regulator) in the mouth for several hours a day beginning 3 weeks before the dive. 
(2) For 2 or 3 days before a saturation dive, aquanauts should rest. Aggressive teams never catch up on rest once the dive commences. Heavy work that might cause minor injuries should be avoided.

(3) Male divers should continue to shave as whisker stubble on the upper lip irritates the skin after about 3 days when the face mask is in place for long periods.

(4) Resistance to dill, even in semi-tropical waters, drops as a mission progresses. Aquanauts wanting to maximize excursion time should have at least a complete $1 / 4$-inch wet suit where water temperatures are $75^{\circ}$ to $82^{\circ} \mathrm{F}$,

(5) Minor cuts or scrapes worsen during a saturation dive. Replacing wet bandages between excursions to allow some drying of the wound reduces the danger of infection.

(6) Ear infections are common among divers working in semi-tropical waters. Some divers flush their ears after each dive using an alcohol and vinegar solution or use a portable hair dryer to dry the ears for preventative care.

\section{Recommendations for habitats in saturation diving programs}

As a result of their experiences, the authors have formed some general conclusions about requirements for ideal underwater habitats. They believe an undersea laboratory should have low construction, maintenance, and operating costs. It must be highly mobile and quickly deployable on a variety of ocean floors. The ideal habitat will have storage and working space as well as comfortable living quarters for extended missions. It should be compatible with a wide variety of mission goals.

More specifically, it should be at least at two-room facility, self-contained (such as Hydro-Lab), and operate on appropriate gas mixtures to about 150 feet. Based upon the views presented throughout this paper, we suggest a number of specific minimum features for a habitat:

\section{Dry compartment (living space)}

Four bunks (of which two are convertible into work counters), two large domed viewing ports, temperature and humidity control, sink with running water, microwave oven, freezer, shelves, carpet, sound-absorbing wall and ceiling insulation, controlled lighting for work areas, an open microphone capability-to-surface support, and habitat serving as primary decompression facility.

\section{Wet room}

Entry trunk large enough for two fully equipped divers to surface, wide steps on ladder with hand rails, portable showerhead and curtain, non-skid floor with slope to promote water runoff, one large vicwing port, well-designed chemical or dischargetype toilet, pull-down wall counters, shelves, wet-suit rack, scuba tank filler-hose, well-protected open microphone in or very close to entry trunk, and a water heater. 


\section{External features}

A distance of 5 feet or more between entry and base or sea bed, high-output light near each viewing port with internal switch near port, light near trunk entry, portable lamp with 200 feet of cord, spare scuba tank racks, and gear storage enclosures.

\section{Surface support vessel}

An unsinkable life-support barge equipped with high-pressure breathing air compressor and storage, air supply for habitat, freshwater storage tank, navigational lights, antenna tower, and electricity generator.

The authors recognize that not all attributes and deficiencies of underwater habitats have been discussed here. Their goal was not to criticize those programs mentioned but to bring to light some problems encountered by aquanauts working from habitats and to contribute to improve construction and equipment of such habitats.

\section{SUMMARY}

1. The assessment of three undersea habitats - Tektite, Hydro-Lab and Edalhab is based primarily upon the experience of the authors during a total of 62 man-days under saturation diving conditions while conducting biological research programs.

2. A number of desirable and undesirable features were found in each habitat system; none of the individual systems included all of the desirable features.

3. The paper discusses advantages and disadvantages of various features of the habitats including work and living areas, support equipment and techniques, operations and safety. The authors offer their experiences and suggestions to contribute to improvement of habitats and undersea diving operations.

\section{LITERATURE CITED}

Nowlis, D., WatTER, H. H. \& Wortz, E. C., 1971. Habitability assessment program. In: Tektite II: Scientists-in-the-sea. Ed. by J. W. Miller, J. G. VanDerwalker \& R. A. Waller. U.S. Dept. Int., Washington, D.C., VIII 68-89.

Smith, M. C., Huber, C., Swaney, G. A. \& STadler, C., 1971. Tektite II food system. In: Tektite II: Scientists-in-the-sea. Ed. by T. W. Miller, J. G. VanDerwalker \& R. A. WALlER. U.S. Dept. Int., Washington, D.C., VIII 90-95.

TENNEY, J. B., 1971. 2400 hours of saturation diving: A statistical analysis of Tektite II. Scuba Safety Rep. Ser. (Univ. Rhode Isl. Dep. oceanog. eng.) 4, 1-69.

Waller, R. A., 1971. Facilities. In: Tektite II: Seientists-in-the-sea. Ed. by J. W. Mrruer, J. G. VANDer Walker \& R. A. Waller. U.S. Dep. Int., Washington, D.C. II 1-18.

First author's address: W. L. HrgH

NOAA Northwest Fisheries Center

Division of Marine Fish and Shellfish

2725 Montlake Blvd. E.

Seattle, Washington 98112

USA 